\title{
Heart failure: role and point of view of cardiac intensivist
}

\author{
Maria Benedetto ${ }^{1}$, Ludovica Nardozi ${ }^{1}$, Georgiana Luisa Baca ${ }^{2}$, Antonio Loforte ${ }^{3}$, Massimo Baiocchi ${ }^{1}$ \\ ${ }^{1}$ Cardiothoracic and Vascular Anesthesia and Intensive Care Unit, Sant' Orsola Malpighi University Hospital, Bologna, Italy; ${ }^{2}$ Barts Heart Center, St. \\ Bartholomew's Hospital, London, UK; ${ }^{3}$ Cardiothoracic Department, Sant' Orsola Malpighi University Hospital, Bologna, Italy \\ Contributions: (I) Conception and design: None; (II) Administrative support: None; (III) Provision of study materials or patients: None; (IV) \\ Collection and assembly of data: None; (V) Data analysis and interpretation: None; (VI) Manuscript writing: All authors; (VII) Final approval of \\ manuscript: All authors. \\ Correspondence to: Maria Benedetto. Cardiothoracic and Vascular Anesthesia and Intensive Care Unit, Sant' Orsola Malpighi University Hospital, \\ Bologna, Italy. Email: mariabenedettoanestesista@gmail.com.
}

\begin{abstract}
Heart failure is an acute or chronic syndrome where the heart is unable to provide adequate amount of oxygen to body tissues. The treatment of heart failure aims to give an immediate answer in terms of regression of volume overload and restoration of hemodynamic stability and then to ensure management of clinical exacerbation, reduction in hospital stay, and increasing of survival. The pharmacological treatment of heart failure includes drugs with different strength of evidence. When the patient is no more responsive to medical therapy a non-pharmacological approach may be required. The first step is cardiac resynchronization therapy and implantable cardiac defibrillator. Then hospitalization and inotropic support may be needed. When cardiac disease reaches the end stage, the severe decrease in multi organ perfusion requires a quick therapeutic response. This is a time dependent scenario, when mechanical circulatory support (MCS) plays a crucial role. MCS may be used as temporary hemodynamic support on situations where myocardial recovery is likely, such as after revascularization and in cases of fulminant acute myocarditis. Conversion to ventricular assist devices or transplantation should be considered if longer duration of MCS is required. Advances in the treatment of cardiogenic shock patients in terms of pharmacological therapies, short term and long term MCS could provide opportunities to improve survival, but they also increase the complexity of clinical care. For this reason a multidisciplinary shock team approach is paramount for early symptom detection, to guide initial haemodynamic therapy and for the right choice of MCS device at the right time.
\end{abstract}

Keywords: Cardiogenic shock; inotropes; mechanical circulatory support; intensivist

Submitted Mar 10, 2020. Accepted for publication May 28, 2020.

doi: $10.21037 / \mathrm{cdt}-20-339$

View this article at: http://dx.doi.org/10.21037/cdt-20-339

\section{Background of heart failure and cardiogenic shock}

Heart failure (HF) is a clinical syndrome with acute and chronic stages where the heart is unable to provide an adequate amount of oxygen to body tissues.

The pump collapse leads to circulatory failure, with systemic arterial hypotension, clinical signs of tissue hypoperfusion and hyperlactatemia.

This clinical condition is the cardiogenic shock (CS), as described by Vincent et al. (1). HF affects $2-3 \%$ of adult population over 65 years of age. Only $33 \%$ of affected patients survives the first five years from diagnosis and the $25 \%$ survives five years from the first hospital admission. According to the American Heart Association (AHA) heart failure has a progressive evolution with five stages of disease. Stage 1 refers to structural heart disease with onset of initial symptoms; the patient feels weak and reports chest pain or dyspnea in the context of mild to moderate exertion; at this stage a medical therapy is indicated. Stage 2 is when initial symptoms become stable, with a variable clinical plateau length. Stage 3 refers to a decline in the functional status, with intermittent exacerbations of symptoms and some preserved response to medical therapy. 


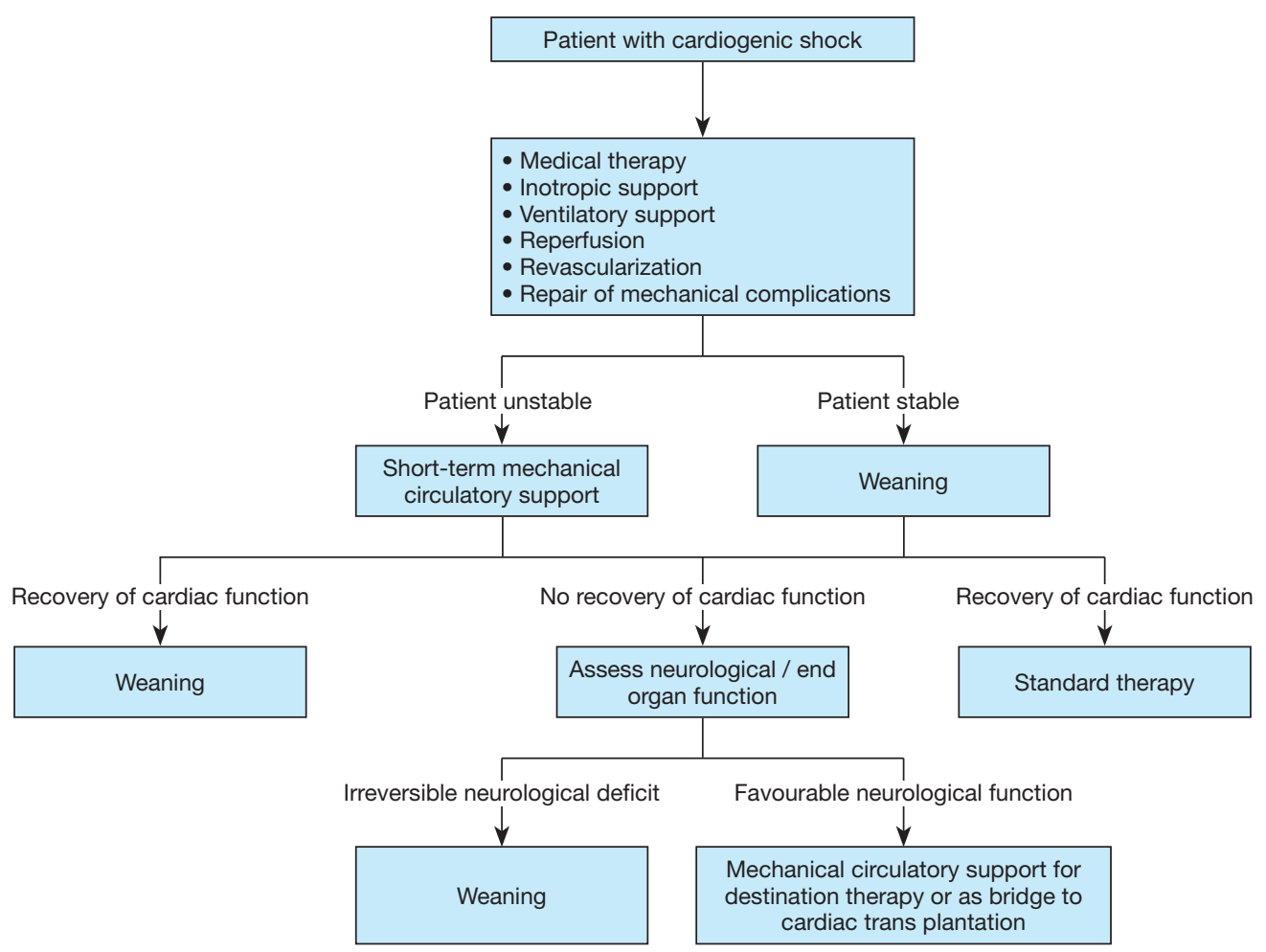

Figure 1 Algorithm for management of patients with cardiogenic shock.

In stage 4 symptoms of heart failure become refractory to standard medical therapy.

Stage five is the end stage of the disease, when mechanical circulatory support (MCS) or heart transplant are needed $(2,3)$.

In this scenario a multidisciplinary team approach to manage rapidly deteriorating patients is recommended. The team should include a cardiologist, a cardiothoracic surgeon and a cardiac intensivist. The latter is called to play a prominent role in a multidisciplinary team, especially in the late stages of the heart disease, when the standard medical therapy fails and the patient shows the first signs of shock. He can identify shock signs and aetiology, asses the severity of cardiocirculatory failure and quickly adopt a tailored invasive hemodynamic therapy guided by invasive heart monitoring (transoesophageal echocardiography, Pulmonary Artery Catheter, mixed venous saturation).

\section{Pharmacological management of cardiogenic shock}

When cardiac disease reaches the final stage, we talk about CS. The severe decreasing in multi organ perfusion requires a quick therapeutic response (Figure 1).

The first goal in the treatment of acute heart failure and cardiogenic shock is to give an immediate answer in terms of regression of volume overload and restoration of hemodynamic stability.

When standard medical therapy is no more sufficient on the cardiology ward, the patient is evaluated by the ICU intensivist in order to increase the level of monitorization and admit to the intensive care if needed. In this setting invasive arterial pressure line, central line catheter, calculation of fluid net balance and echocardiographic assessment of heart function are mandatory before starting the inotropic support. The use of inotropes requires the specific expertise of the ICU specialist. All inotropic drugs share the same effect of intracellular calcium level increase. Milrinone and Dobutamine are the only Food and Drug Administration approved inotropes. They are recommended by the guidelines of the European Society of Cardiology (ESC) in 2018 and the European Association of Cardiothoracic Surgeons (EACTS), once medical therapy fails and before initiating the ventilatory support.

However, they are not recommended for acute exacerbations in ischemic patients $(4,5)$. 
Inotropes may have several side effects such as coronary perfusion pressure decrease, low efficacy in beta-blocked patients, peripheral vasodilation, but above all boosted myocardial oxygen consumption. The latter may cause an increased incidence of arrythmia, impaired diastolic relaxation, myocardial ischemia and, as a consequence, a worse prognosis.

A relatively new drug, often used by intensivists in cases of severe heart failure, alone or in association with other inotropes, is Levosimendan. Levosimendan is an inodilator indicated for short term treatment. It increases cardiac contractility by increasing sensitivity of troponin C to calcium. It provides vasodilation by opening $\mathrm{K}+\mathrm{ATP}$ channels in smooth muscle cells of arterial vessels and ensures cardioprotection by opening $\mathrm{K}+\mathrm{ATP}$ channels in cardiac mitochondria (6).

Repeated scheduled infusions of Levosimendan in patients with refractory HF have showed a decreased hospital admission rate due to disease exacerbation (7).

However, literature is still unclear and an original article from Landoni et al. published in The New England Fournal of Medicine showed no difference in 30-day mortality in patients undergoing cardiac surgery and treated with lowdose Levosimendan, in addition to standard care, when compared to placebo (8).

Rapid identification of shocked patients despite maximal drug support and fast transition from inotropic drugs to mechanical support is crucial for patient survival.

However, before the decision to escalate the treatment there are important aspects to be taken into consideration. Firstly, authors have recently pointed out that there is insufficient consensus in stratifying correctly the true endstage patients and to help find the more appropriate and early treatment.

Fedele et al. proposed and interesting new TNM (tumour, lymph node, metastasis) like classification. This is based on a new point of view in HF that takes inspiration from cancer disease staging. It takes into account the myocardial damage $(\mathrm{T})$, the HF staging and lung involvement $(\mathrm{N})$, and the "the malfunction" of peripheral organs $(\mathrm{M})$, like oncology metastasis staging (9).

This new prognostic score could be useful for early detection of patients who have contraindications to medical therapy and need early mechanical circulatory support (MCS) $(10,11)$. Moreover, in this time dependent clinical scenario of cardiogenic shock, a central role of the intensive care physician is to bring together the cardiology and cardiac surgery expertise in order to find the best solution to support the patient with the right MCS at the right time.

\section{Mechanical circulatory support in cardiogenic shock}

There are short term and long term MCS $(12,13)$ (Figure 2).

Examples of short term MCS are intra-aortic balloon pump (IABP), Impella (2.5 and 5.0), Tandem Heart, CentriMag and Veno-Arterial Extracorporeal Membrane Oxygenation (VA ECMO). Ideal Candidates are INTERMACS 2 patients. These devices are sometimes used in combination (ECMO + IABP, Impella + ECMO, $\mathrm{ECMO}+$ Impella). Impella catheter (2.5-5.0) has got a percutaneous access route, it is floated across the aortic valve and the inflow orifice is positioned into the left ventricle. The Impella was approved by the FDA to be used within the first six hours from CS onset.

TandemHeart is another percutaneous ventricular assist device, with a short-term continuous flow centrifugal assist device that can offer extracorporeal left ventricular support up to a maximum of 14 days. A percutaneous cannula is floated through the femoral vein, across the interatrial septum towards the left atrium; oxygenated blood is taken from the left atrium and returned into the femoral artery. The TandemHeart can circulate up to $5 \mathrm{~L}$ per minute of blood. Its insertion requires a skilled team and can be done only in the operating room or in the cath lab.

CentriMag is a magnetically levitated circulatory pump that extracorporeally provides centrifugal continuous-flow support to both right and left ventricles for a maximum of 30 days. It can circulate up to $9 \mathrm{~L}$ per minute of blood and must be positioned in the operating room through sternotomy (14).

VA ECMO may have both a central or peripheral configuration. Through a central cannulation, the blood is drained directly from the right atrium and returned to the proximal ascending aorta. With a peripheral cannulation, the blood is drained from the proximal great veins (generally femoral vein), using a surgically cut-down or modified Seldinger technique, and returned to the aorta via the axillary or femoral artery cannulation $(15,16)$.

The intensivist is dealing with such devices and has the crucial role to decide when the patient is ready to be weaned. The most common scenario is the weaning from VA ECMO, either central or peripheral. During central VA ECMO the heart is completely put at rest and completely offloaded. During this period no inotropic support is generally provided. During peripheral VA ECMO it 
INTERMACS SCORE

Interagency Registry for Mechanically Assisted Circulatory Support

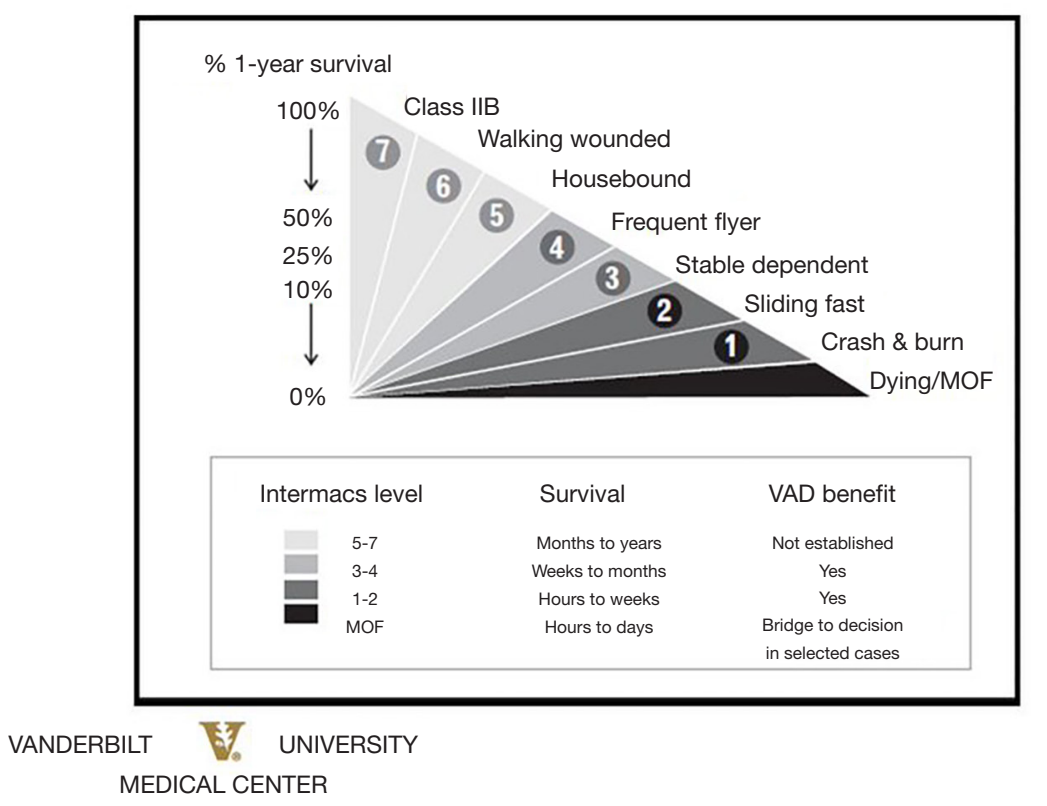

Long-Term LVAD

Ideal candidates are

INTERMACS classes 3-4

Short-Term LVAD

Candidates are

INTERMACS classes 1-2

Not a LVAD Candidate

INTERMACS 1 or those with

multisystem organ failure

Lietz and Miller

Curr Opin Cardiol

2009, 24:246-251

Figure 2 Indications for assist device therapy depending on INTERMACS level.

is always important to contemplate the risk of related pulmonary oedema. For this reason, the transpulmonary venting is often considered. However, when left ventricle is not decompressed, a negative fluid net balance should always be ensured, and a certain grade of aortic valve opening be guaranteed. In this contest, a IABP in addition to peripheral VA ECMO is often positioned in order to reduce the cardiac afterload and improve peripheral microperfusion. After a mean average of time of 5 to10 days an ECMO weaning trial should be generally considered. The weaning trial is performed by reducing the ECMO flow and contemporary increasing the inotropic support, and evaluating how the heart is behaving in terms of preload hemodynamic parameters (central venous pressure, wedge pressure), arterial systemic and pulmonary pressures, and in terms of biventricular performance assessed via ultrasound.

The long-term MCS currently available are the left ventricular assist device (LVAD) and the total artificial heart (TAH). Several studies have established the efficacy of LVADs in patients with a left ventricular function less than $25 \%$, who were inotrope dependent and have advanced heart failure symptoms (New York Heart Association (NYHA) class IIIb and IV despite optimal medical therapy).

For patients undergoing cardiac transplant evaluation, a maximal oxygen consumption (VO2 uptake) less than $12 \mathrm{~mL} / \mathrm{kg} / \mathrm{min}$ is considered as an indication for "bridgeto-transplant" or "destination therapy" with LVAD. Contraindications to long-term MCS placement such as advanced age (major than 60-65 years of age), severe frailty, severe coagulopathy, irreversible multi-organ failure must always be considered.

Cardiac cachexia (CC), due to advanced age, metabolic and neurohormonal abnormalities is common (19\%) in patients with advanced HF together with malignancies (34\%) and chronic obstructive pulmonary disease (29\%) and may impact the clinical decision-making (17).

Advanced severe right ventricular failure is associate with poor hemodynamics and the patients are not good candidates for LVAD alone. Levosimendan prior to LVAD implantation may be used to reduce the risk of right ventricular failure, although evidence is limited $(18,19)$.

Biventricular support with two implantable or extracorporeal pumps or implantation of a TAH should be considered. Patients presenting with acute biventricular failure could initially be treated with a biventricular assist device and then transitioned to a LVAD support, after a period of right ventricular unloading.

MCS may play a role as bridge to recovery, bridge to 
Table 1 Indications and contraindications for left ventricle assisted devices (LVAD)

\begin{tabular}{|c|c|c|c|}
\hline Indications & $\begin{array}{l}\text { Strong indications } \\
\text { (BR, BT, DT) }\end{array}$ & $\begin{array}{l}\text { Moderate indications } \\
\text { (especially for DT) }\end{array}$ & Contra indications \\
\hline \multirow{13}{*}{$\begin{array}{l}\text { Bridge to } \\
\text { recovery } \\
\text { (BR); Bridge } \\
\text { to decision } \\
\text { (BD); Bridge to } \\
\text { transplant (BT); } \\
\text { Destination } \\
\text { therapy (DT) }\end{array}$} & $\begin{array}{l}\text { NYHA Class IV for } 60 \text { to } \\
90 \text { days }\end{array}$ & NYHA IV for 30 days & $\begin{array}{l}\text { Acute cardiogenic shock or arrest with uncertain neurologic } \\
\text { status }\end{array}$ \\
\hline & $\begin{array}{l}\text { Maximum tolerated medical } \\
\text { therapy and certified } \\
\text { respiratory therapy and CRT/ } \\
\text { ICD if indicated }\end{array}$ & $\begin{array}{l}\text { Maximal tolerated } \\
\text { medical therapy and } \\
\text { CRT/ICD if indicated }\end{array}$ & $\begin{array}{l}\text { Irreversible contraindications to heart transplantation if } \\
\text { destination or recovery is not the aim }\end{array}$ \\
\hline & $\begin{array}{l}\text { Chronic dependence on } \\
\text { ionotropes }\end{array}$ & $\begin{array}{l}\text { Intermittent inotrope } \\
\text { dependency }\end{array}$ & Non-systolic heart failure (HF) \\
\hline & LVEF $<25 \%$ & LVEF $<25 \%$ & Co-existing illness with life expectancy $<2$ years \\
\hline & Peak VO2 <12 mL/kg/min & $\begin{array}{l}\text { Peak VO2 } \\
<12 \mathrm{~mL} / \mathrm{kg} / \mathrm{min}\end{array}$ & $\begin{array}{l}\text { Terminal severe comorbidities; renal disease (haemodialysis } \\
\text { or creatinine }>2.5-5 \mathrm{mg} / \mathrm{dL} \text { ), advanced cancer, severe liver } \\
\text { disease (spontaneous INR }>2.5 \text {, bilirubin }>5 \mathrm{mg} / \mathrm{dL} \text {, severe } \\
\text { lung disease, unresolved stroke or severe neuromuscular } \\
\text { disorder }\end{array}$ \\
\hline & $\mathrm{PCWP} \geq 20 \mathrm{mmHg}$ & & Active systemic infection or significant risk of infection \\
\hline & $\mathrm{SBP} \leq 80-90 \mathrm{mmHg}$ & & Active severe bleeding \\
\hline & $\mathrm{Cl} \leq 2 \mathrm{~L} / \mathrm{min} / \mathrm{m}^{2}$ & & Chronic platelet count $<50,000 \times 10^{9}$ per $\mathrm{L}$ \\
\hline & & & Antibody-confirmed heparin induced \\
\hline & & & Right HF not secondary to left HF \\
\hline & & & Significant aortic insufficiency that will not be corrected \\
\hline & & & $\begin{array}{l}\text { Mechanical aortic valve that will not be converted to } \\
\text { bioprosthesis }\end{array}$ \\
\hline & & & $\begin{array}{l}\text { Psychosocial limitations, e.g., inability to comply with } \\
\text { medical regimen or device and driveline maintenance or to } \\
\text { interpret alarms }\end{array}$ \\
\hline
\end{tabular}

NYHA, New York Heart Association; LVEF, left ventricular ejection failure; SBP, systolic blood pressure; CRT, cardiac resynchronisation therapy; $\mathrm{Cl}$, cardiac index; ICD, intra-cardiac defibrillator; PCWP, pulmonary capillary wedge pressure.

transplant or destination therapy.

Use of MCS as a bridge to recovery may be appropriate in situations where myocardial recovery is anticipated such in patients with "stunned" myocardium or in patients presenting with acute fulminant myocarditis. In both of these cases, conversion to mechanical ventricular assist devices or transplantation should be considered if longer duration of support is required and when recovery is unlikely. Direct bridging from extracorporeal life support (ECLS) to heart transplantation is associated with poorer 1 year post-transplant survival (20) (Table 1).

After long term MCS implantation, preload should be optimized to ensure adequate LVAD flows, but without overloading of the right ventricle (RV). Titration of fluid 
challenge with TOE and the central venous pressure are essential. Early criteria of RV failure following LVAD placement are cardiac output $(\mathrm{CO})<2.0 \mathrm{~L} / \mathrm{min} / \mathrm{m}$, mixed venous oxygen saturation $(\mathrm{SvO} 2)<55 \%$ and mean arterial pressure (MAP) $<50 \mathrm{mmHg}$ (21). The need of high inotropic support and RV dilatation, together with excessive offload of the left ventricle should suggest the addition of temporary MCS for RV support (22).

Given the potential for recovery, all patients with nonischemic cardiomyopathy should be managed as potential bridge to recovery candidates. Thresholds for device removal include a cardiac index $(\mathrm{CI})>2.6 \mathrm{~L} / \mathrm{min} / \mathrm{m}$, pulmonary artery wedge pressure $<16 \mathrm{mmHg}$ and right atrial pressure $<10 \mathrm{mmHg}(23,24)$.

As we can see from ELSO registry, the use of these systems has dramatically increased in the last ten years. However, despite the significant efforts made to improve the treatment of the CS through mechanical circulatory support and the optimization of medical therapy, the literature still does not offer a satisfactory conclusion to be unanimously put in practice. The SHOCK (Should We Emergently Revascularize Occluded Coronaries for Cardiogenic Shock) trial was conducted when the only percutaneous form of cardiopulmonary support was the IABP. Since then, multiple devices (as mentioned before) have been developed and studied in the setting of CS.

After the publication of Shock Trial in 1999 which showed that early revascularization means lower mortality, no subsequent trials have demonstrated a clear benefit from mechanical or procedural interventions in acute CS. Even those who survive acute intervention may later develop CS and the overall 30-day mortality for patients with CS in association with myocardial infarction is approximately 40 $50 \%$. Unfortunately, this incidence has not changed in the past 20 years since the publication of the landmark SHOCK trial $(25,26)$.

A meta-analysis of four randomized control trials compared the efficacy and safety of percutaneous active MCS (TandemHeart and Impella) vs. control with IABP and demonstrated similar short-term mortality despite initial beneficial effects on systemic pressure increase and lactate level reduction. In both studies, however, a higher rate of bleeding and incidence of limb ischaemia in MCS group was observed $(27,28)$. However, despite the early impact on hemodynamics CS mortality remains high with no prospective randomized trials demonstrating significantly improved mortality with use of percutaneous MCS devices (29).

\section{Discussion}

A new system describing stages of CS from A to E have been developed (30). Stage A is "at risk" for cardiogenic shock, stage B is "beginning" of cardiogenic shock, stage $\mathrm{C}$ is "classic" cardiogenic shock, stage D is "deteriorating", and $\mathrm{E}$ is "extremis".

This classification is easy to apply across the care spectrum from pre-hospital to intensive care providers, but it must be validated by future studies in order to assess the utility and potential prognostic implications.

The INTERMACS classification is useful to categorize CS patients. INTERMACS profile 1 is "crash and burn", profile 2 is "sliding on inotropes", and profile 3 is "dependent stability". Although there is a temporary circulatory support modifier, the INTERMACS classification does not distinguish between patients, for example, who were placed on ECMO support for refractory cardiac arrest from patients who are stable on multiple inotropes and an IABP and those who received an Impella catheter to improve cardiac output while on inotropes. In view of these limitations, comparison of outcome across different retrospective cohorts is difficult.

Furthermore, cardiogenic shock is not only a matter of reduced blood flow or perfusion pressure, but a cascade of events that causes systemic inflammatory response, reduction in vascular tone, high risk of infections. This cascade of events cannot be simply reversed by providing a mechanical support. The crucial factor is timing, choice of the right mechanical support and early treatment of eventual complications related to MCS, because such patients are very frail.

The solution could be the creation of a specialised group with medical professionals specifically trained in the treatment of these patients, a multidisciplinary shock team which includes the cardiologist, cardiothoracic surgeon, cardiac anaesthetist and cardiac intensivist. Only a multidisciplinary team may promptly identify the onset of cardiogenic shock with right examination and monitoring, and start the adequate support as soon as possible $(31,32)$.

\section{Conclusions}

Advances in the treatment of cardiogenic shock patients in terms of pharmacological therapies, short term and long term MCS could provide opportunities to improve survival rates for patients with heart failure, but they also increase the complexity of the clinical care. For this reason 
a multidisciplinary shock team approach is paramount for the early detection of patients at risk, to guide the initial hemodynamic therapy, the right choice of MCS and for a timely and safe procedure. In such team the cardiac intensivist is crucial because he can not only identify but also appropriately treat the most acute and severe cases, through prompt insertion of percutaneous mechanical circulatory assist devices (in particular VA ECMO), and then manage the device weaning and escalation of therapy.

\section{Acknowledgments}

This paper was presented in the joint session of the 27th Annual Meeting of the ISMCS 2019 and RHICS Expert forum, October 21-23, 2019, Bologna, Italy.

Funding: None.

\section{Footnote}

Provenance and Peer Review: This article was commissioned by the Guest Editor (Roland Hetzer) for the series "Heart Failure in the Young and Old: Insights into Various Therapies" published in Cardiovascular Diagnosis and Therapy. The article has undergone external peer review.

Conflicts of Interest: The authors have completed the ICMJE uniform disclosure form (available at http://dx. doi. org/10. 21037/cdt-20-339). The series "Heart Failure in the Young and Old: Insights into Various Therapies" was commissioned by the editorial office without any funding or sponsorship. The authors have no other conflicts of interest to declare.

Ethical Statement: The authors are accountable for all aspects of the work in ensuring that questions related to the accuracy or integrity of any part of the work are appropriately investigated and resolved.

Open Access Statement: This is an Open Access article distributed in accordance with the Creative Commons Attribution-NonCommercial-NoDerivs 4.0 International License (CC BY-NC-ND 4.0), which permits the noncommercial replication and distribution of the article with the strict proviso that no changes or edits are made and the original work is properly cited (including links to both the formal publication through the relevant DOI and the license). See: https://creativecommons.org/licenses/by-nc-nd/4.0/.

\section{References}

1. Vincent JL, De Backer D. Circulatory shock. N Engl J Med 2013;369:1726-34.

2. Yancy CW, Jessup M, Bozkur B, et al. 2013 ACCF/ACC guidelines for the management of heart failure: a report of the American College of Cardiology Foundation/American Heart Association Task Force on Practice Guidelines. J Am Coll Cardiol 2013;62:e147-239.

3. McDonagh TA. Challenges in Advanced Chronic Heart Failure: Drug Therapy. Future Cardiol 2008;4:517-25.

4. Teerlink JR. Overview of randomized clinical trials in acute heart failure syndromes. Am J Cardiol 2005;96:59G-67G.

5. Neumann FJ, Sousa-Uva M, Ahlsson A, et al. 2018 ESC/ EACTS Guidelines on myocardial revascularization. The Task Force on myocardial revascularization of the European Society of Cardiology (ESC) and European Association for Cardio-Thoracic Surgery (EACTS). G Ital Cardiol (Rome) 2019;20:1S-61S.

6. Pollesello P, Ovaska M, Kaivola J, et al. Binding of a new $\mathrm{Ca} 2+$ sensitizer, Levosimendan, to recombinant human cardiac troponin C. A molecular modelling, fluorescence probe, and proton nuclear magnetic resonance study. J Biol Chem 1994;269:28584-90.

7. Oliva F, Perna E, Marini M, et al. Scheduled intermittent inotropes for Ambulatory Advanced Heart Failure. The RELEVANT-HF multicentre collaboration. Int J Cardiol 2018;272:255-9.

8. Landoni G, Lomivorotov VV, Alvaro G, et al. Levosimendan for Hemodynamic Support after Cardiac Surgery. N Engl J Med 2017;376:2021-31.

9. Fedele F, Gatto MC, D'Ambrosi A, et al. TNM-like classification: a new proposed method for heart failure staging. ScientificWorldJournal 2013;2013:175925.

10. Fedele F, Severino P, Calcagno S, et al. Heart failure: TNM-like classification. J Am Coll Cardiol 2014;63:1959-60.

11. Peterson PN, Rumsfeld JS, Liang L, et al. Treatment and Risk in Heart Failure Gaps in Evidence or Quality? Circulation 2010;3:309-15.

12. Lund LH, Matthews J, Aaronson K. Patient selection for left ventricular assist devices. Eur J Heart Fail 2010;12:434-43.

13. Schibilsky D, Haller C, Lange B, et al. Extracorporeal life support prior to left ventricular assist device implantation leads to improvement of the patients INTERMACS levels and outcome. PLoS One 2017;12:e0174262.

14. Alkhouli M, Osman M, Elsisy MFA, et al. Mechanical 
Circulatory Support in Patients with Cardiogenic Shock.

Curr Treat Options Cardiovasc Med 2020;22:4.

15. Lafç $G$, Budak AB, Yener AÜ, et al. Use of extracorporeal membrane oxygenation in adults. Heart Lung Circ 2014;23:10-23.

16. Sigurdardottir V, Bjortuft O, Eiskjær H, et al. Long-term follow-up of lung and heart transplant recipients with pre-transplant malignancies. J Heart Lung Transplant 2012;31:1276-80.

17. Loncar G, Springer J, Anker M, et al. Cardiac cachexia: hic et nunc. J Cachexia Sarcopenia Muscle 2016;7:246-60.

18. Theiss HD, Grabmaier U, Kreissl N, et al.

Preconditioning with Levosimendan before implantation of left ventricular assist devices. Artif Organs 2014;38:231-4.

19. Sponga S, Ivanitskaia E, Potapov E, et al. Preoperative treatment with levosimendan in candidates for mechanical circulatory support. ASAIO J 2012;58:6-11.

20. Levin AP, Jaramillo N, Garan AR, et al. Outcomes of contemporary mechanical circulatory support device configurations in patients with severe biventricular failure. J Thorac Cardiovasc Surg 2016;151:530-5.e2.

21. Lim HS, Howell N, Ranasinghe A. Extracorporeal Life Support: Physiological Concepts and Clinical Outcomes. J Card Fail 2017;23:181-96.

22. Kirsch M, Mazzucotelli JP, Roussel JC, et al. Survival after biventricular mechanical circulatory support: does the type of device matter? J Heart Lung Transplant 2012;31:501-8.

23. Potapov E, Meyer D, Swaminathan M, et al. Inhaled nitric oxide after left ventricular assist device implantation: a prospective, randomized, double-blind, multicenter, placebo controlled trial. J Heart Lung Transplant 2011;30:870-8.

24. Loforte A, Stepanenko A, Potapov EV, et al. Temporary right ventricular mechanical support in high-risk left ventricular assist device recipients versus permanent biventricular or total artificial heart support. Artif Organs 2013;37:523-30.

Cite this article as: Benedetto M, Nardozi L, Baca GL, Loforte A, Baiocchi M. Heart failure: role and point of view of cardiac intensivist. Cardiovasc Diagn Ther 2021;11(1):301-308. doi: $10.21037 / \mathrm{cdt}-20-339$
25. Hochman JS, Buller CE, Sleeper LA, et al. Cardiogenic shock complicating acute myocardial infarctionetiologies, management and outcome: a report from the SHOCK Trial Registry. Should we emergently revascularize occluded coronaries for cardiogenic shock. J Am Coll Cardiol 2000;36:1063-70.

26. Hochman JS, Sleeper LA, Webb JG, et al. Early revascularization in acute myocardial infarction complicated by cardiogenic SHOCK. SHOCK Investigators. Should we emergently revascularize occluded coronaries for cardiogenic shock. N Engl J Med 1999;341:625-34.

27. Rios SA, Bravo CA, Weinreich M, et al. Meta-analysis and trial sequential analysis comparing percutaneous ventricular assist devices versus intra-aortic balloon pump during high-risk percutaneous coronary intervention or cardiogenic shock. Am J Cardiol 2018;122:1330-8.

28. Alushi B, Douedari A, Froehlig G, et al., Impella versus IABP in acute myocardial infarction complicated by cardiogenic shock. Open Heart 2019;6:e000987.

29. Thiele H, Akin I, Sandri M, et al. One-year outcomes after PCI strategies in cardiogenic shock. N Engl J Med 2018;379:1699-710.

30. Baran DA, Grines CL, Bailey S, et al. SCAI clinical expert consensus statement on the classification of cardiogenic shock: This document was endorsed by the American College of Cardiology (ACC), the American Heart Association (AHA), the Society of Critical Care Medicine (SCCM), and the Society of Thoracic Surgeons (STS) in April 2019. Catheter Cardiovasc Interv 2019;94:29-37.

31. Tehrani B, Truesdell A, Singh R, et al. Implementation of a Cardiogenic Shock Team and Clinical Outcomes (INOVASHOCK Registry): Observational and Retrospective Study. JMIR Res Protoc 2018;7:e160.

32. Taleb I, Koliopoulou AG, Tandar A, et al. Shock Team Approach in Refractory Cardiogenic Shock Requiring Short-Term Mechanical Circulatory Support: A Proof of Concept. Circulation 2019;140:98-100. 